\title{
Finding the Optimal Operating Point for Service Production Processes via Simulation
}

\author{
Guenther Schuh, Philipp Jussen, Christian Fabry, and Gerhard Gudergan \\ Institute for Industrial Management (FIR), Pontdriesch 14/16, 52062 Aachen, Germany \\ \{G.Schuh, Philipp.Jussen, Christian.Fabry, Gerhard.Gudergan\} \\ afir.rwth-aachen.de
}

\begin{abstract}
This paper presents a simulation approach for service production processes on the basis of which an optimal operating point for service systems can be identified. The approach specifically takes into account the characteristics of human behavior. The simulation is based on a system theory approach to the service delivery process. A specific use case of the simulation approach is presented in detail to illustrate how characteristic curves are deduced and an optimal operating point is obtained.
\end{abstract}

Keywords: Service production, service process, simulation, service productivity.

\section{Introduction}

Increasing operational productivity is the basis for improving competitiveness of industrial services [1]. Services are characterized by their intangible nature leading to a lack of storability [2]. Furthermore, the customer is involved in the production process of the service. He is not only especially aware of the service production process, but also participates in the process as an external production factor [3]. An analysis of productivity in service systems should incorporate both the quality and the process character of service delivery [4]. The inclusion of quality into the assessment of productivity consequently leads to the inclusion of the factors time, cost and capacity. For an assessment of service productivity this ultimately means the consideration of all five dimensions and their interactions with one another [5].

Past research results illustrate the ability and the value of simulation in the design of highly flexible business processes [6]. In a service context, specific applications of simulation which aim at improving the operational understanding of the service production process have been researched scientifically [7]. This paper presents a simulation approach for service systems. As a result of the simulation characteristic curves for services systems are obtained in order to find an optimal operating point.

\section{The Elasticity of Capacity in Service Systems}

The theory for industrial production mostly assumes constant process times which for example do not depend on the amount of load or input on a system [8]. For services, 
the process times are subject to larger fluctuations and actual productivity differs significantly from the theoretically calculated performance [9]. The service delivery process has a determining human component, usually because a service process operates on employee labor as a major resource or capacity [10]. It is therefore essential to include the aspects of human nature into the consideration.

Humans are aware and therefore influenced by their environment and their current situation [11]. The productivity of a human depends not only on the capabilities of the human itself but also on the environmental state in which the human is being put into. For example, the human performance is viewed as a function of its ability and its motivation [12]. According to the Yerkes-Dodson law the performance on a specific task is a direct function of the psychological or mental arousal [13]. Similar relationships are known for the effects of stress on the work performance [14].

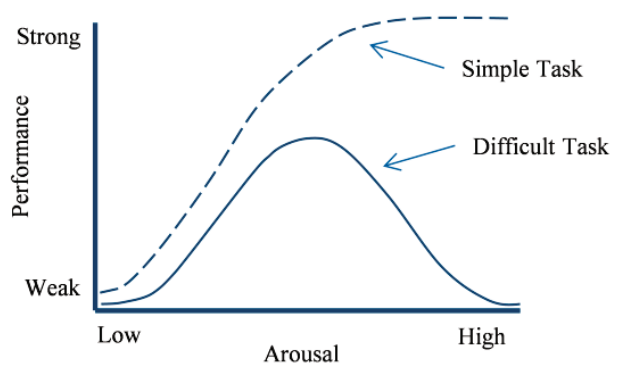

Fig. 1. Yerkes-Dodson law [13]

In recent scientific research the term procrastination describes the impact of the organization of the work on the human performance [15][16]. Humans tend to put off more urgent tasks in order to do something else, which typically brings them more personal pleasure or enjoyment [17]. Ariely (2002) showed that by setting multiple periodic deadlines instead of heaving one single deadline at the end, the performance for a specific task could be increased significantly. At the same time the average delay of the task was reduced [18]. Recent research suggest, that procrastination is not merely an issue of setting deadlines and organizing work, but occurs in various forms in all types of work settings and for most human beings[19][20].

Altogether the implications derived from scientific literature in the field of psychology led to two basic assumptions about the human component in the service delivery processes:

- Depending on the nature of the task, the time and the quality of a service process are not constant but show a certain elasticity towards environmental factors.

- As the human performance depends on a variety of factors (such as motivation, stress, arousal), an examination of service productivity should therefore consider the same factors as they determine the outcome of a service process. 


\section{Simulation Model Construction}

In order to capture the characteristics of human behavior into a simulation model a system theory approach is taken. The system theory is used for modeling relationships in complex organizational structures such as productions systems [21]. A generic tool for structuring a system model is provided by the approach of Negele (1998), which was developed on the basis of system theory. The so-called ZOPH approach divides an overall system into four types of systems [22]: The target system, the object system, the process system and the actor system. Elements outside the system boundaries are part of the system environment. Figure 2 illustrates the elements and aspects of service production that are included in the simulation.

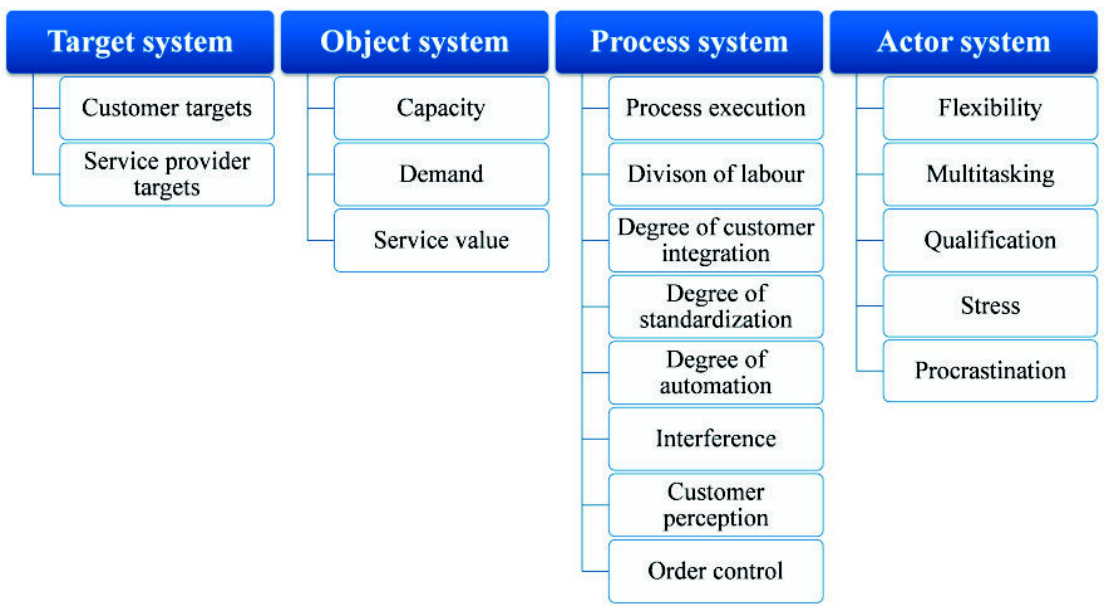

Fig. 2. Elements and aspects included in the simulation model

In this paper an application of the simulation approach for a specific use case is presented. The use case is based on a real technical service center. In the service center, which has the basic characteristics of a call center, technical service for specific technical products such as wireless routers is provided. Owners or operators of the products can call the service center in case of a malfunction of the product. The service center staff helps the customer via telephone and tries to solve the problem together with the customer. Problems can be detected not only in theory but are also addressed in a practical way because the service center staff can reconstruct the real configurations on a special workbench. If a problem solution can't be obtained on the phone, the customer is asked to send in their device. For this use case this is considered as a nonfulfillment of customer requirements.

The following bullet points describe each of the factors included in the simulation model:

- The system has a certain constant capacity. The capacity is derived from the number of staff working in the service center. It's the theoretical amount of work (number of calls) a certain amount of staff can do in a fixed period of time. 


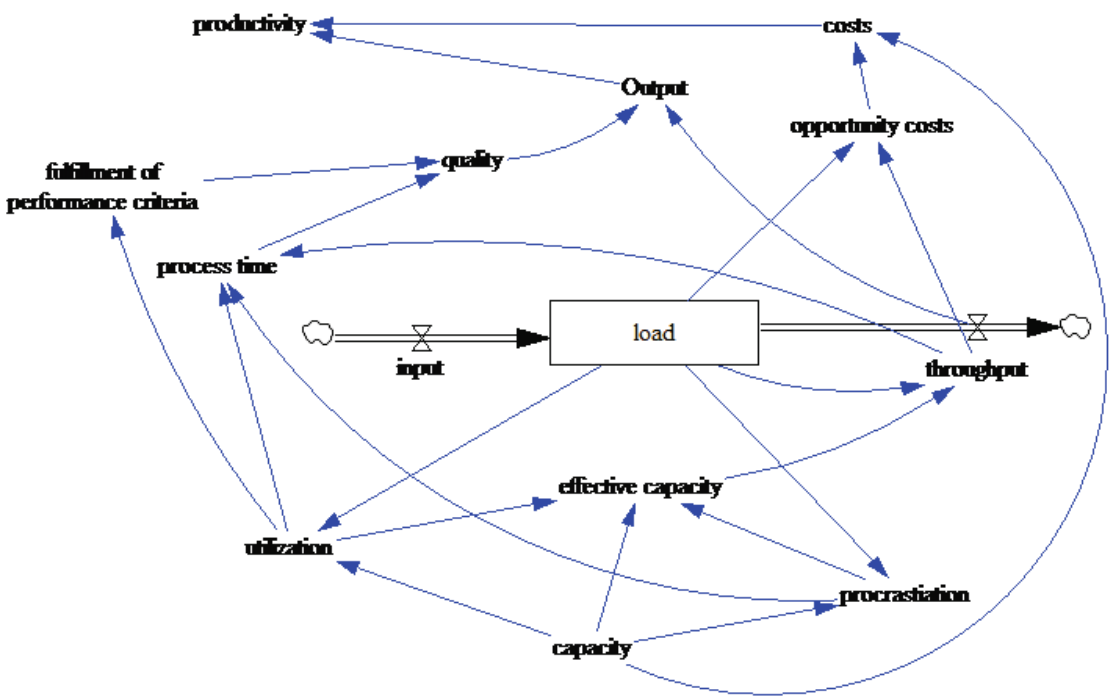

Fig. 3. Simulation model for a service center

- The input represents the amount of calls from customers to the service center. It is a fluctuating demand with a constant mean and standard deviation.

- The input adds to a load for the system for a fixed time period. The load can be viewed as the workload (number of calls) during a fixed period of time.

- The utilization is derived from the comparison of the load and the capacity. The utilization is used to determine the effects of stress due to high workload. For the utilization a maximal value was included since for a given amount of capacity the workload can't be infinitely high. Also the telephone system of the service center has an automatic cap which only allows for a limited number of calls to be forwarded to the staff. Data provided by the service center allowed for the calculation of this utilization cap.

- The procrastination depends on the capacity and the load. If the load is bigger in comparison to the capacity a lesser level of procrastination will occur and vice versa. It is assumed that procrastination occurs while a task is performed (a member of the staff is answering a call from a customer). A practical example for procrastination during task performance in this case is exaggerated chatting with the customer (a certain amount of friendly conversation is imperative). The effects of procrastination will also occur in between tasks (staff taking longer breaks, chatting with other staff, etc.).

- The effective capacity takes into accounts the effects of procrastination and stress due to high workload. It manifests the concept of the elasticity of capacity in service systems. Although the capacity is kept constant the effective capacity varies depending on the workload. 
- The throughput is determined by the effective capacity. It is the performance (answered number of calls) in a fixed period of time. The throughput is subtracted from the load.

- The opportunity costs arise, if the load in a fixed period is bigger than the throughput. In this specific case the difference between the load and the throughput (number of unanswered calls) can't be carried over to the next period and thus leads to opportunity costs.

- The costs are the sum of the costs for the capacity and the opportunity costs. In this specific case all other costs are assumed to be constant and do not depend on the number of staff in the service center.

- The process time depends on the utilization and the level of procrastination. High levels of procrastination lead to increased process times. A high utilization leads to a decrease in process time, since a larger amount of work has to be done in the same fixed period of time.

- The fulfillment of performance criteria can be viewed as the number of tasks that are successfully performed. A successful performance depends on the fulfillment of the demands a customer has on a task. In this specific case the customer calls the service center and expects a solution to his or hers problem. If a solution can't be given (the product is still malfunctioning after the call and has to be sent in) there is no fulfillment of performance criteria. A high utilization leads to stress which leads to a lower average performance of the service center staff (diagnosing and solving a technical problem over the phone with the help of the customer with little or no technical expertise is categorized as a difficult task).

- The perceived quality depends on the fulfillment of the performance criteria and the process time. From a customer point of view a lesser fulfillment of performance criteria and longer process time mean a decrease in perceived quality. For this specific case the two factors are weighed against each other in a way that the fulfillment of the performance criteria has a significantly larger effect on the perceived quality than the process time. The effects of a non-fulfillment of the performance criteria for the customer are more significant since the product is still malfunctioning and the customer has to do the extra work of sending it in. Also the customer expects his problem to be solved by the service center but has not a certain expectation towards an amount of time the solution has to be given in (apart from as quick as possible).

- The overall output is determined by the throughput and the quality. For service processes the productivity cannot be judged solely on quantitative values but also has to take into account qualitative aspects (as pointed out in chapter 2). Therefor an output consisting of the quantitative throughput and the perceived quality is calculated.

- The productivity is the given by comparing the output and input (costs) of the service system.

Further key assumptions included in the simulation model are the following:

- For the actor system it was determined that no multitasking occurs (staff do not answer two phonecalls at the same time). Also each staff member is sufficiently 
qualified for the task and qualification does not differ significantly amongst the staff.

- An order control was assumed in a way that incoming calls into the service center are kept in a queue if no staff was available to answer the call. But only a certain amount of waiting time was allowed for the customer. After the customer has spent that time waiting in the queue he was disconnected and asked to try at a later time. For the simulation model the waiting time of the customer was assumed to not play a significant role, since it was kept relatively small by the queuing system.

\section{$4 \quad$ Finding the Optimal Operating Point via Simulation}

For the presentation of the results in this paper all quantitative data was normalized due to data security and privacy issues of the service center's company. The results in this paper were generated in order to show the general principle of the characteristic curves and how an optimal operating point for a service system can be obtained. In order to generate results the capacity was given different values. For each value for the capacity a simulation run over a certain amount of time periods was conducted.
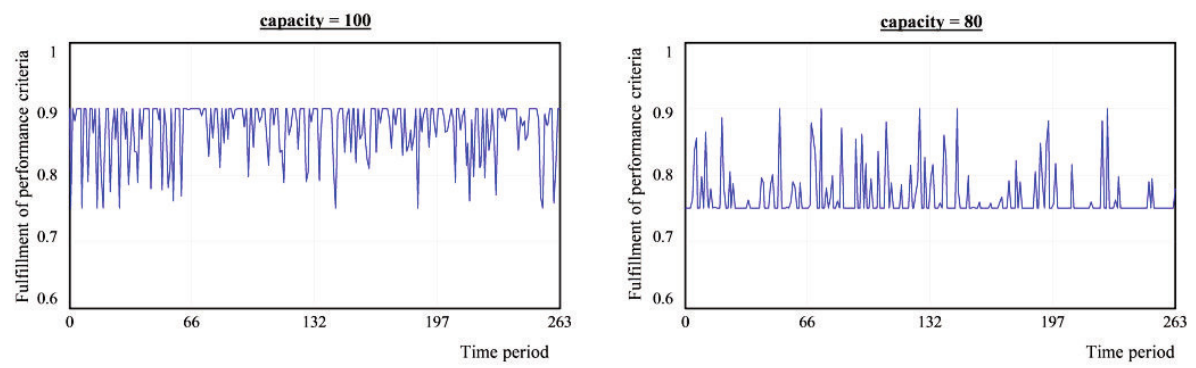

Fig. 4. Fulfillment of performance criteria for different capacities

Figure 4 illustrates how the fulfillment of performance criteria, as a major part of the perceived quality, changed for different values of capacity. For a capacity of 100 the maximal fulfillment of performance criteria is at 0.9 or $90 \%$. This is due to the fact that for 1 out of 10 calls it was assumed that there was no solution to the problem and the product had to be sent in in any case. The fulfillment drops to 0.75 or $75 \%$ in periods with high demand and a large load. For a capacity of 80 the maximal fulfillment of performance criteria was seldomly reached. In most periods the fulfillment of performance criteria drops down to 0.75 or $75 \%$. Due to the utilization cap, which was implemented in order to limit the workload for the service center staff, the fulfillment of performance criteria does not drop below this value.

In order to obtain the optimal operating point the productivity has to be maximized. For each value of capacity the resulting average productivity calculated over the time periods. By plotting the different capacities on one scale and the resulting averages for productivity on the other a characteristic curve is obtained. The optimal operating 
point for the service system is located at the top of the bell shaped curve. It is the point where the capacity of the service center is used most productively taking into account all the factors described in the simulation model.
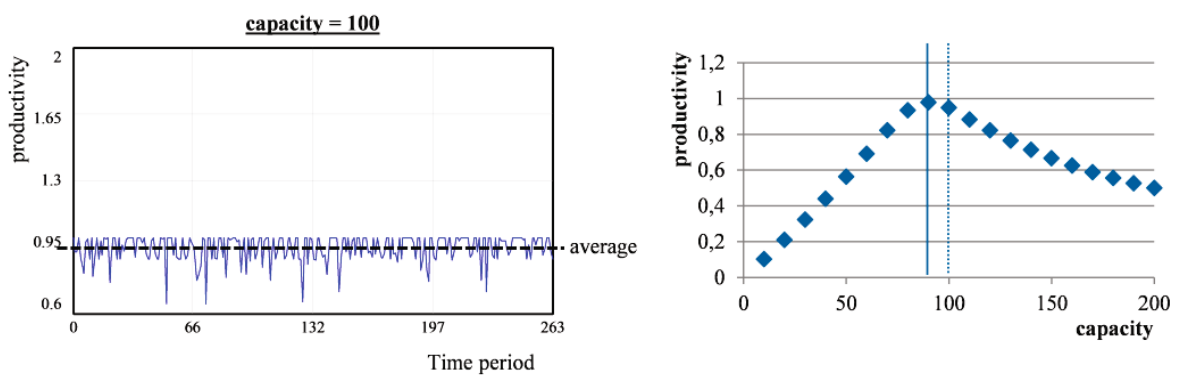

Fig. 5. Obtaining the optimal operating point

\section{$5 \quad$ Summary and Outlook}

This paper has presented an approach for simulating service delivery systems. A major assumption for the simulation approach is that capacity derived from human workforce shows the same characteristics as human behavior does. Additionally, a use case for the simulation approach was introduced on the basis of which characteristic curves were described in order to find an optimal operating point for the service system. Further research could focus on including demand which not only fluctuates but also changes its mean over time. Also, a process chain with different types of processes with customer requirements and preferences to quality can be integrated into the simulation approach. The challenge would then be to assess and simulate the interactions between the different processes. Also further research could focus on avoiding or controlling the effects of human behavior (such as procrastination) in order to improve service productivity. For example the application of the principle of tact for service processes can be a solution.

\section{References}

1. Grönroos, C., Ojasalo, K.: Service Productivity. Towards a conceptualization of the transformation of inputs into economic results in services. Journal of Business Research 57(4), 414-423 (2004)

2. Frietsche, U., Maleri, R.: Dienstleistungsproduktion. In: Bullinger, H.-J., Scheer, A.-W. (eds.) Service Engineering, pp. 195-225. Springer, Berlin (2006)

3. Meier, H., Roy, R., Seliger, G.: Industrial Product-Service Systems - IPS2. Annals of the CIRP - Manufacturing Technology 59, 607-627 (2010)

4. Waltemode, S., Aurich, J.C.: Productivity and Quality Assessment of Services within technical Product-Service Systems. In: Proceedings of the 4th CIRP International Conference on Industrial Product-Service Systems. Springer, Heidelberg (2013) 
5. Lasshof, B.: Produktivität von Dienstleistungen. Mitwirkung und Einfluss des Kunden. 1. Auflage. Dt. Univ.-Verl, Wiesbaden (2006)

6. Mühlbauer, K.: System Dynamics als Instrument zur Optimierung hochflexibler Geschäftsprozesse. Information Management \& Consulting 2011(04), 85-91 (2011)

7. Oliva, R., Bean, M.: Developing operational understanding of service quality through a simulation environment. International Journal of Service Industry Management 19(2), $160-175$ (2008)

8. Nyhuis, P., Wiendahl, H.-P.: Logistische Kennlinien. Springer, Berlin (2012)

9. Höck, M.: Dienstleistungsmanagement aus produktionswirtschaftlicher Sicht. Dt. Unib.Verl., Wiesbaden (2005)

10. Fitzsimmons, J., Fitzsimmons, M.: Service Management. McGraw-Hill/Irwin, Boston (2008)

11. Chmiel, N.: An introduction to work and organizational psychology. Blackwell Pub., Malden (2009)

12. Campbell, J., Pritchard, R.: Motivation Theory in Industrial and Organizational Psychology. In: Dunnette (ed.) Handbook of industrial and organizational Psychology, pp. 63-130 (1976)

13. Yerkes, R., Dodson, J.: The Relation of Strength of Stimulus to Rapidity of HabitFormation. Journal of Comparative Neurology and Psychology 18, 459-482 (1908)

14. Hancock, P., Vasmatzidis, I.: Human occupational and performance limits under stress: the thermal environment as a prototypical example. Ergonomics 41(8), 1169-1191 (1998)

15. Brunner, M.: Elektronik ist anders - Ein Leitfaden für Unternehmer, Qualitätsmanager, Produkt- und Projektmanager mit wenig oder keinem Elektronikwissen zur erfolgreichen Entwicklung, Fertigung und Markteinführung von Produkten mit eingebetteter Elektronik und Software. Books on Demand, Norderstedt (2011)

16. Techt, U., Lörz, H.: Critical Chain - Beschleunigen Sie Ihr Projektmanagement, Haufe, Freiburg im Breisgau (2007)

17. Steel, P., Brothen, T., Wambach, C.: Procrastination and personality, performance, and mood. Personality and Individual Differences 30, 95-106 (2001)

18. Ariely, D., Wertenbroch, K.: Procrastination, Deadlines, and Performance: Self-Control by Precommitment. Psychological Science 13(3), 219-224 (2002)

19. Hammer, C., Ferrari, J.: Differential Incidence of Procrastination Between Blue and White-Collar Workers. Current Psychology: Development, Learning, Personality, Social 21(4), 333-338 (2002)

20. Gupta, R., Hershey, D., Gaur, J.: Time Perspective and Procrastination in the Workplace: An Empirical Investigation. Current Psychology: Development, Learning, Personality, Social 31(2), 195-211 (2012)

21. Wiendahl, H.: Betriebsorganisation für Ingenieure. Carl Hanser, München (2010)

22. Negele, H.: Systemtechnische Methodik zur ganzheitlichen Modellierung am Beispiel der integrierten Produktentwicklung. München (1998) 